\title{
Efficacy of Antenatal Intravenous Immunoglobulin Treatment in Pregnancies at High Risk due to Alloimmunization to Red Blood Cells
}

\author{
Beate Mayer $^{\mathrm{a}}$ Larry Hinkson $^{\mathrm{b}}$ Wiebke Hillebrand ${ }^{\mathrm{b}}$ Wolfgang Henrich $^{\mathrm{b}}$ \\ Abdulgabar Salamac \\ ${ }^{a}$ Institute of Transfusion Medicine, Charité - Universitätsmedizin Berlin, Campus Virchow-Klinikum, Berlin, Germany; \\ ${ }^{b}$ Department of Obstetrics, Charité - Universitätsmedizin Berlin, Campus Virchow-Klinikum, Berlin, Germany; \\ ${ }^{\mathrm{c}}$ Department of Gynecology, Charité - Universitätsmedizin Berlin, Campus Virchow-Klinikum, Berlin, Germany
}

\section{Keywords}

Intravenous immunoglobulins · Pregnancy .

RBC antibodies - Alloimmunization · Fetal loss

\section{Summary \\ Background: Alloimmunization to red blood cells (RBCs) may result in fetal anemia prior to 20 weeks gestation. The question as to whether early commencement of an- tenatal treatment with high-dose intravenous immuno- globulins (IVIG) may prevent or at least delay the devel- opment of fetal anemia in the presence of alloantibodies to RBCs is highly relevant. Patients and Results: Here we describe a patient with high-titer anti-K and two other se- verely affected pregnant women with a history of recur- rent pregnancy loss due to high-titer anti-D or anti-D plus anti-C. Early commencement of treatment with IVIG $(1 \mathrm{~g} / \mathrm{kg} /$ week) resulted in prevention of intrauterine trans- fusion (IUT) in the former two cases, and in a significant delay of development of fetal anemia in the remaining case (26 weeks gestation). Conclusion: Based on our findings and of previously published cases, early initia- tion of treatment of severely alloimmunized women with IVIG (1 $\mathrm{g} / \mathrm{kg} /$ week) could potentially improve the out- come of fetuses at risk. \\ (C) 2018 S. Karger GmbH, Freiburg}

\section{Introduction}

The true extent of perinatal loss due to alloimmunization to RBCs is unknown. However in developed countries, 1:300 to 1:600 pregnancies are at risk for hemolytic disease of the fetus and new- born (HDFN) due to RBC alloimmunization [1-5]. Approximately $30 \%$ of affected fetuses may require in utero or postnatal interventions with an estimated overall morbidity of $0.1 \%$ and a mortality rate of $0.002 \%$ [6]. While alloimmunization to RBCs has been reduced during the last five decades because of the administration of anti-D immunoprophylaxis to $\mathrm{RhD}$-negative women and by Rhesus and Kell antigen-matched blood transfusion in women of childbearing age [7], prenatal loss due to uncontrolled immunization still represents a severe complication in perinatal health. In addition, more than $50 \mathrm{RBC}$ antigens are now known to cause HDFN [8]. Specialized interventions to prevent clinically significant alloimmunization to the RBC RhD antigen as well as strategies for the management of all fetuses at risk of anemia have continued to improve over the last decades. These developments include the detection of the causative antibodies, the implementation of intraperitoneal and later intravascular intrauterine blood transfusion (IUT) $[9,10]$, the diagnostic use of amniocentesis [11, 12], the introduction of anti-D prophylaxis [13], and, finally, the replacement of amniocentesis by the non-invasive Doppler ultrasound measurement of the fetal middle cerebral artery peak systolic velocity (MCA-PSV) [14-16].

Currently, the survival rate for alloimmunization to RBCs exceeds $80 \%$ in specialized centers all over the world [17-19]. However, IUT is not always possible and is potentially associated with morbidity and mortality, especially if performed before 20 weeks of gestation or in the presence of fetal hydrops [17, 20-26]. Overall, procedure-related complications and fetal loss rates are $1.2-4.9 \%$ and $0.6-1.6 \%$ per procedure, respectively $[20,27,28]$. Importantly, fetal loss increases threefold if IUT is performed before 20 weeks of gestation [29]. Therefore, the question concerning how to manage fetuses that may develop significant anemia before IUT becomes possible is warranted.

\section{KARGER}

(c) 2018 S. Karger GmbH, Freiburs

Fax +497614520714 
In this study, we describe three severely affected pregnancies, of which two resulted in live births without any intrauterine interventions and in one pregnancy in which IUT was postponed by early commencement of treatment with high-dose intravenous immunoglobulins (IVIG; $1 \mathrm{~g} / \mathrm{kg} /$ week). A detailed discussion on the available literature using this treatment option since its introduction in 1965 is also provided [30].

\section{Material and Methods}

Serological testing was performed using standard gel techniques (Bio-Rad, Cressier sur Morat, Switzerland, or Grifols Deutschland GmbH, Frankfurt/M., Germany). Blood group antigens for Rhesus (D, C, E, c and e) and Kell (K and k) were determined by hemagglutination in gel cards using monoclonal reagents (BioRad or Grifols Deutschland $\mathrm{GmbH}$ ).

Serum and eluate indirect antiglobulin tests (IAT) and direct antiglobulin test (DAT) were performed using polyspecific Ig cards. Eluate from the newborn's RBCs was prepared using the acid method (BAG, Lich, Germany). Antibody titrations were performed with maternal plasma collected prior to IVIG infusion. For comparison, the freshly obtained sample was diluted in saline and analyzed in parallel with the last tested sample by the IAT using the gel technique and commercially available test cells (Bio-Rad or Grifols Deutschland $\mathrm{GmbH})$. Genotyping for KEL and for paternal RHD zygosity was performed after DNA extraction using PCR-SSP (BAG).

IVIG was administered weekly ( $1 \mathrm{~g} / \mathrm{kg})$; however, in one patient, the required dose was unable to be administered four times. Fetuses were monitored by ultrasound to confirm gestational age and by middle cerebral artery-peak systolic velocity (MCA-PSV) to monitor fetal hemoglobin ( $\mathrm{Hb})$.

\section{Case Presentations and Results}

\section{Case 1}

Case 1 was a 34-year old Caucasian woman who presented in her second pregnancy for monitoring of a newly diagnosed alloimmunization due to anti-K. The father's blood group was confirmed as KK. IVIG treatment was started at gestational week 14 and repeated assessment of MCA-PSV showed no signs of fetal anemia. The antibody titer for anti-K remained almost unchanged throughout the pregnancy (fig. 1).

After delivery, the DAT was strongly positive, and maternal anti-K antibody could be eluted from the neonate's RBCs. The child's blood group was determined as $\mathrm{O}$ Rh-positive, and Kk was confirmed by genotyping. The newborn had a $\mathrm{Hb}$ of $15.7 \mathrm{~g} / \mathrm{dl}$ and a total bilirubin of $12.68 \mathrm{mg} / \mathrm{dl}$; therefore, therapy for hyperbilirubinemia was not required. However, shortly after delivery, the $\mathrm{Hb}$ of the newborn gradually declined, with a nadir of $6.9 \mathrm{~g} / \mathrm{dl}$ at the age of 7 weeks. As reticulocytes were within normal limits, the decline in $\mathrm{Hb}$ was most likely due to the known myelosuppressive effect of anti-K [31]. No therapy was administered. After a 2-week period, there was a spontaneous increase of $\mathrm{Hb}$ to $10.2 \mathrm{~g} / \mathrm{dl}$.

\section{Case 2}

Case 2 was a 36 -year-old woman in her 10th pregnancy. She had only one live birth (1st pregnancy) and all other pregnancies were fatal. She had four stillbirths (one after and three before 37 weeks of gestation), two miscarriages after 16 weeks of gestation, and two abortions. Anti-D was detected in her serum. Other abnormalities that may be associated with pregnancy loss were largely excluded. The last two pregnancies were in Germany, with the remaining pregnancies in Turkmenistan. The mother had been informed that her fetuses had an 'accumulation of fluid'. Since the father was confirmed to be homozygously D-positive, HDFN due to severe rhesus alloimmunization was the most likely cause for the previous fetal demise. Her anti-D titer was 2,048 during early pregnancy. She was commenced on high-dose IVIG at week 14 of pregnancy. Her antiD titer remained almost unchanged during pregnancy (fig. 1). MCA-PSV was within normal limits throughout the entire pregnancy. At $35+5$ weeks of gestation, labor was induced, and a healthy boy with a cord blood $\mathrm{Hb}$ of $15.2 \mathrm{~g} / \mathrm{dl}$ was delivered. However, the newborn's DAT was strongly positive, and maternal anti$\mathrm{D}$ could be eluted. The baby's blood group was O Rh-positive. Phototherapy was commenced immediately, but his $\mathrm{Hb}$ declined gradually after birth and bilirubin levels increased to a maximum 20.3 $\mathrm{mg} / \mathrm{dl}$. The newborn received three transfusions during the first 8 postnatal weeks due to significant anemia. His anemia could only be explained by anti-D and hemolysis.

Case 3

Case 3 was a 27-year-old woman from Syria, with a history of severe $\mathrm{Rh}$ alloimmunization: four of her children died shortly after birth (two after and two before 37 weeks of gestation), and she had one stillbirth at 20 weeks of gestation due to hydrops fetalis. She presented in her 6th pregnancy with a high anti-D titer $(4,096)$ and, in addition, anti-C ( titer 8). Her husband was confirmed to be homozygously D-positive. She was started on IVIG at gestational week 14, but only received 0.6 and $0.8 \mathrm{~g} / \mathrm{kg}$ body weight until week 18. The MCA-PSV started to increase above the upper normal limit from gestational week 23. IUT was performed in the 28th week of gestation, but the fetus was already severely anemic and intrauterine death occurred a few hours after the procedure.

All three women had high antibody titers (>1:256) early in pregnancy. Both women with anti-D had a dramatic history of preterm perinatal mortality due to RBC alloimmunization. Serological details of all three patients, their partners, and the neonates of cases 1 and 2 are provided in table 1 . IVIG was commenced at 14 th week of gestation until delivery in cases 1 and 2, and until 28th week of gestation in case 3 (fig. 1). There were no side effects leading to the interruption of IVIG infusion.

\section{Discussion}

All three cases described in this report suffered from threatening perinatal loss. Indeed, two women also had a medical history of repeated perinatal loss. Although the medical history of the previous pregnancies was somewhat limited, especially in case 2 , the clinical picture involving fetal hydrops, high-titer anti-D, and D homozygosity of the partners clearly indicates that HDFN was the most likely cause of fetal death. Despite their history, both women 


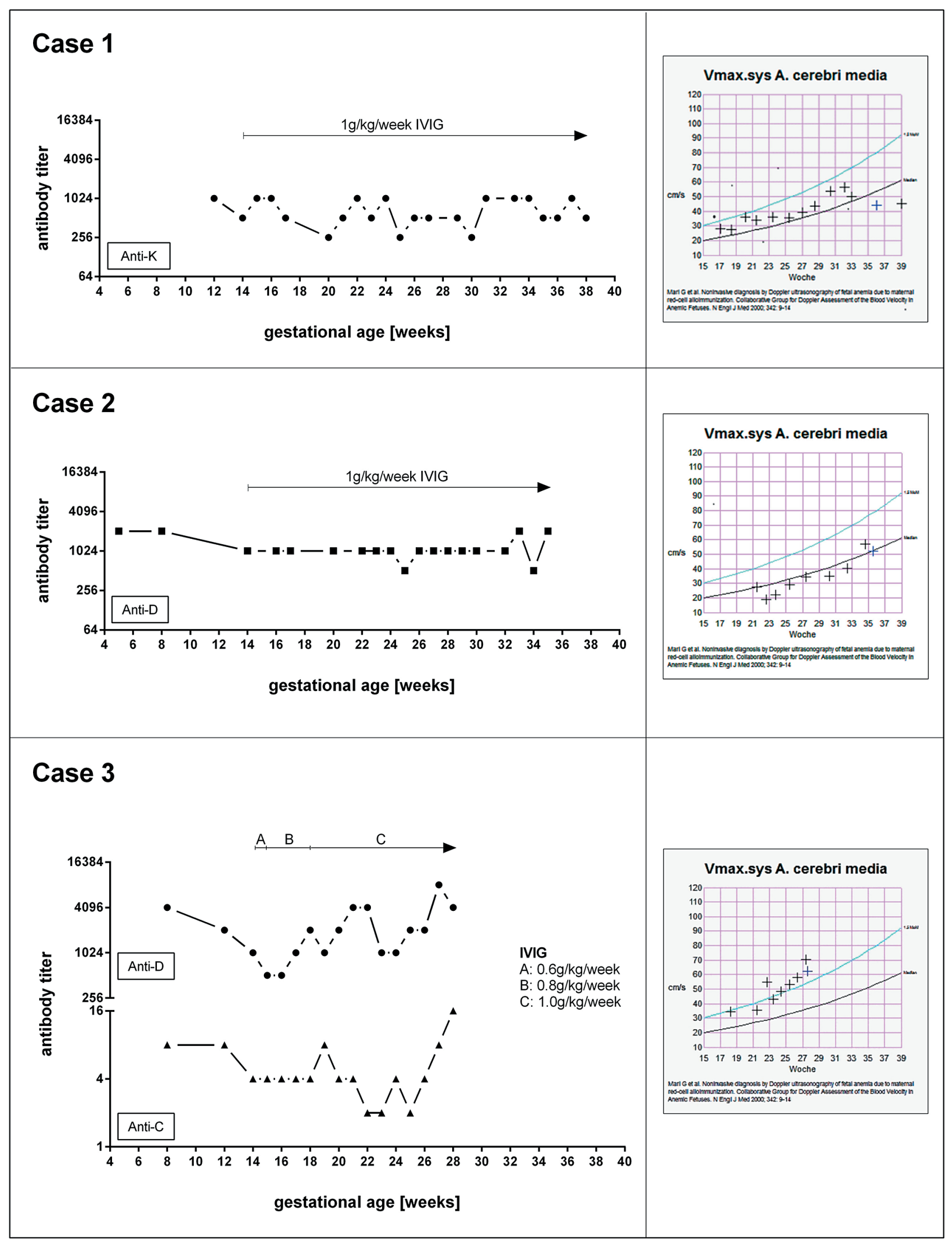

Fig. 1. Antibody titer and middle cerebral artery-peak systolic velocity (MCA-PSV) under administration of high-dose intravenous immunoglobulin. 
Table 1. Serological findings in all 3 cases

\begin{tabular}{|c|c|c|c|c|c|c|}
\hline \multirow{2}{*}{$\begin{array}{l}\text { Case } \\
\text { no. }\end{array}$} & \multicolumn{2}{|l|}{ Mother } & \multirow{2}{*}{$\frac{\text { Father }}{\text { blood group }}$} & \multicolumn{3}{|l|}{ Child } \\
\hline & antibody & blood group & & blood group & DAT & eluate \\
\hline 1 & anti-K & kk (Kel-negative) & $\begin{array}{l}\text { KK (Kel-positive, } \\
\text { homozygous) }\end{array}$ & $\begin{array}{l}\text { Kk (Kel-positive), } \\
\text { heterozygous }\end{array}$ & $4+$ & maternal anti-K \\
\hline 2 & anti-D & RhD-negative & $\begin{array}{l}\mathrm{DD} \text { (RhD-positive, } \\
\text { homozygous) }\end{array}$ & $\begin{array}{l}\text { Dd (RhD-positive, } \\
\text { heterozygous) }\end{array}$ & $4+$ & maternal anti-D \\
\hline 3 & anti-D, C & $\mathrm{RhD}$-negative & $\begin{array}{l}\mathrm{DD} \text { (RhD-positive, } \\
\text { homozygous) }\end{array}$ & n.t. & n.t. & n.t. \\
\hline
\end{tabular}

had planned to become pregnant again. They were informed that their current pregnancies were associated with extremely high risks of perinatal loss. In such affected women, subsequent pregnancies are associated with a more severe disease outcome [32], Therefore, IVIG was considered as the most effective measure to prevent lifethreatening HDFN.

In the first case, anti- $\mathrm{K}$ was detected in the second pregnancy. Therefore, the first pregnancy was not affected by HDFN. As anti$\mathrm{K}$ may not only cause hemolysis but also suppression of fetal erythropoiesis [33], affected fetuses may develop severe anemia. Furthermore, Kell antigens are expressed on fetal RBCs as early as 10-11 weeks of gestation [34]. Hence, fetal anemia may occur before 20 weeks of gestation. In such cases, IUT is associated with high risks or may even be impossible. Following anti-D, the most severe HDFN is caused by anti-K [19]. In a population study from the Netherlands, Koelewijn et al. [1] found $26 \%$ of K-positive fetuses from mothers with anti-K suffered from severe HDFN, with 4 of 5 children requiring in utero intervention. In a study from the UK, severe or very severe disease occurred in $50 \%$ of the affected pregnancies [35]. Based on these facts, the presence of a markedly high antibody titer and a K homozygous partner, the fetus (case 3) was considered to be at high risk of HDFN, which might be minimized or prevented by IVIG therapy.

However, as this treatment is costly, most, if not all, health insurance companies refuse to cover such non-evidence-based treatments. Well-designed, controlled clinical trials in this cohort are potentially difficult not only due to the high costs but also as a result of moral and ethical challenges faced with implementing such randomized studies, therefore making such studies unlikely to be conducted and help in clinical care. There is, however, evidence that IVIG treatment may be useful in certain circumstances. Several case series and case reports indicate a beneficial role of IVIG, at least in delaying the development of significant anemia [36]. Admittedly, focusing on the reported cases in the literature, the administration of IVIG varied considerably and was inadequate due to low doses, delayed administration (after fetal anemia was already present), and/or inconsequent administration in a number of cases (table 2) [30, 37-57]. Only one study has shown that the administration of $1 \mathrm{~g} / \mathrm{kg} /$ week in four women with anti-D did not appear to improve outcomes of affected fetuses [58]. Interestingly, the aforementioned study demonstrated that IVIG was helpful in the management of a pregnant woman with anti-K. Furthermore, the authors report that IVIG treatment was commenced after demonstrating fetal anemia in two cases of the four described patients with anti-D. Of note, the remaining two fetuses received IUT during the very early stage of gestation (weeks 20 and 22, respectively). Most importantly, fetal blood samples were obtained from all affected fetuses on several occasions independent of anemia and IUT. Therefore, the worsening effect on alloimmunization and other side effects due to the used invasive procedures cannot be excluded. Ultimately, at that time, the MCA-PSV technique was not yet available, and the conclusion in the aforementioned study that IVIG does not appear to be useful in the treatment of severe $\mathrm{Rh}$ disease is, in our opinion, incorrect. Similarly, all studies performed before 2000 used invasive diagnostic measures to determine the severity of fetal anemia. At present, old techniques have been replaced by high-resolution ultrasound equipment and experienced perinatologists. In fact, all recent reports indicate an improvement in the outcome of treated patients with IVIG alone or in combination with plasmapheresis or immunoadsorption followed by IVIG administration. Well-designed studies should address whether the primary use of plasmapheresis is required to reduce antibody titers prior to treatment with IVIG.

Our recommendation to commence IVIG administration as early as possible in severely affected patients is supported by other authors who have postulated that the reason for the inconstant benefit of IVIG treatment might be related to the delayed commencement of therapy. Optimal treatment should start before 13 weeks of gestation, when significant placental transfer of IgG from maternal to fetal circulation begins [59]. Administration of the required dose without interruption appears to play a key role in preventing the development of anemia. Although the optimal dose of IVIG is unknown, adapting from its use in maternal platelet immunization a dose of $1 \mathrm{~g} / \mathrm{kg}$ per week appears to be reasonable [60]. Case 3 did not receive the required dose on four occasions during the observation period (fig. 1).

Based on our experience, routine control of antibody titers are highly valuable as a complementary measure to MCA-PSV. A significant correlation between both parameters was observed in all three patients. However, serological testing should be performed 


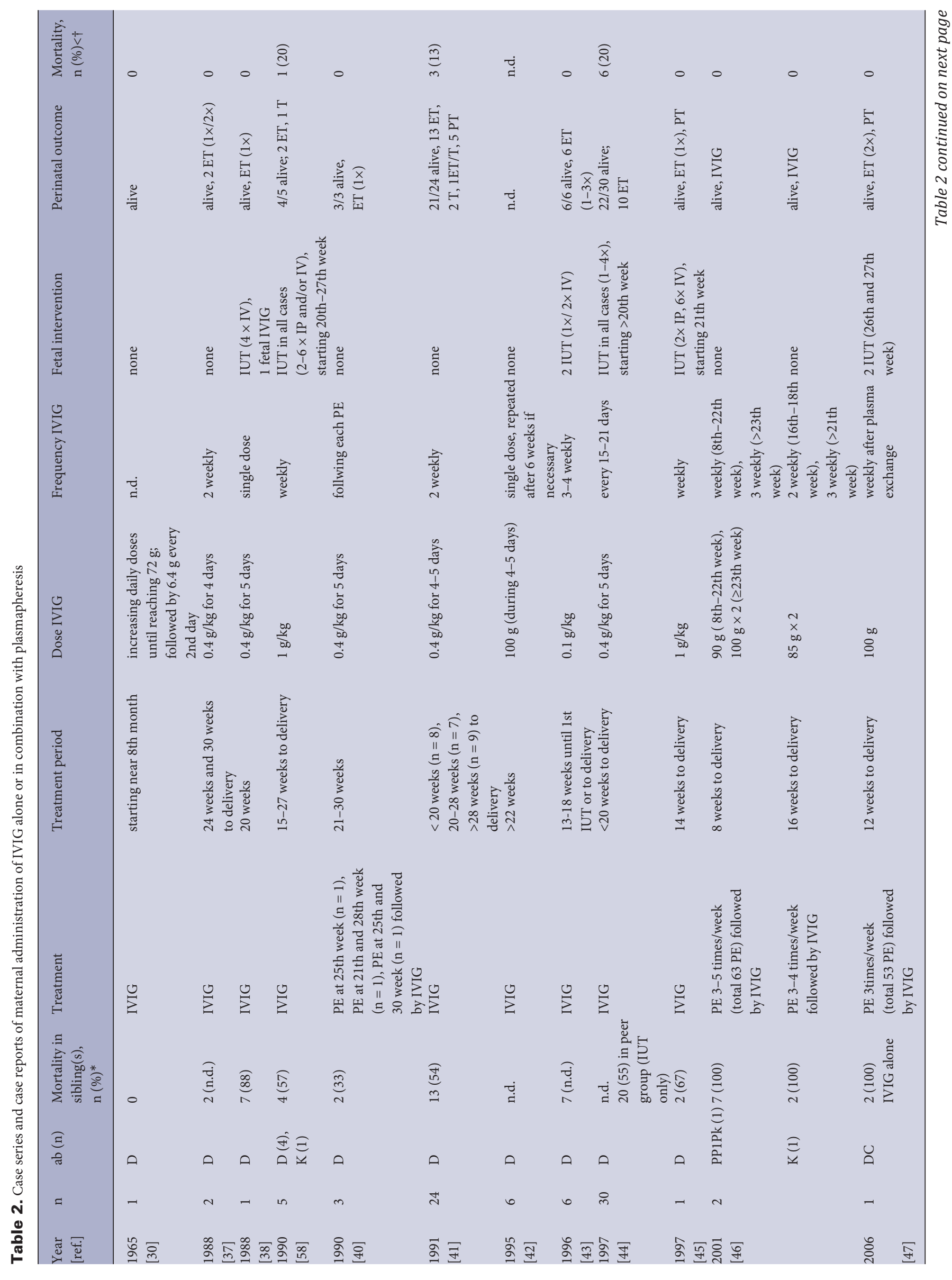




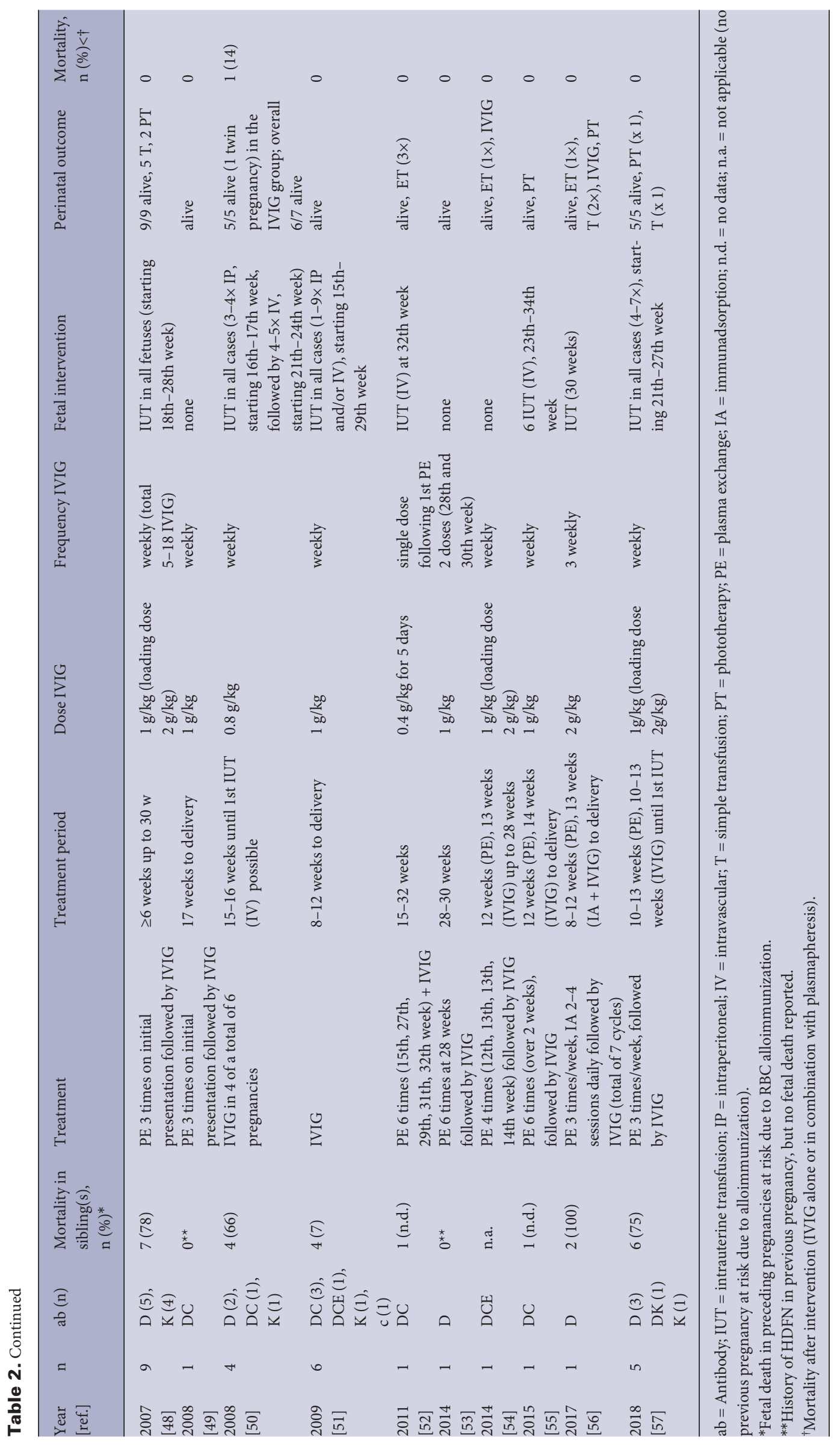


under identical conditions during observation, i.e., using the same technique and well-defined RBCs. Nevertheless, the diagnostic value of antibody titers remains questionable. The correlation between antibody titer and the degree of severity of anemia is more superior in anti-D than in anti-K $[35,61]$. As mentioned above, the later antibody may cause severe HDFN, even at low titers.

The true mode of action of IVIG on different diseases including HDFN is unclear. The following mechanisms may be involved: i) downregulation of the maternal immune response, e.g., by increasing suppressor T-cell function, resulting in the inhibition of maternal antibody synthesis; ii) reduction of antibody transport across the placenta by competitive blocking of Fc receptors; iii) competitive blockage of the $\mathrm{Fc}$ receptors in the reticuloendothelial system, thereby decreasing phagocytosis of antibody-coated fetal RBCs [37, $39,42,45]$; and iv) IVIG may bind to maternal antibodies or enhance their dissociation from antigenic components [62]. Interestingly, both live fetuses developed significant anemia, and blood transfusion was required postpartum in case 2 . The phenomenon that neonates with HDFN may have prolonged anemia for several weeks postpartum can be explained by continuous hemolysis due to maternal antibodies and by suppressed erythropoiesis $[63,64]$. A possible explanation for the development of anemia after birth, despite pretreatment with IVIG, may be related to the reduction of IVIG concentration and thereby its efficacy. The question that remains to be answered is whether or not the half-life of IVIG is shorter than that of the maternal alloantibody in neonates. If this is the case, this may be explained by the saturation of the FcRn receptor, which is responsible for antibody recycling by endothelial or myeloid cells, thereby reducing the IgG catabolism $[65,66]$. How- ever, it remains speculative whether competitive binding of exogenous IVIG and immune maternal antibodies may result in reduced half-life of the former antibodies. Ultimately, alloantibodies are, at least in part, fixed on fetal RBCs and might be degraded by an alternative mechanism to that operating by free antibodies in IVIG.

Several reports have addressed whether IVIG should be administered to fetuses rather than to the affected mother [67-69]. We believe that the results obtained from these studies are inconclusive. Similarly, treatment of affected neonates with IVIG does not appear encouraging [70-72].

Finally, intraperitoneal blood transfusion may be considered in cases where intravascular transfusion is difficult or even impossible, i.e., IUT prior to 20 weeks of gestation. Unfortunately, the delayed IUT in case 3 was primarily related to technical difficulties and maternal obesity. In this case, perinatal loss may have been prevented, if the fetus would have received peritoneal blood transfusion before the occurrence of fetal hydrops.

In summary, our data agree with previously reported cases and suggest the versatility of early IVIG administration as an adjuvant therapy. Compared to historical controls of previous studies, IVIG alone or in combination with plasmapheresis appears to improve fetal outcome and delay or decrease the need for perinatal blood transfusion. However, these promising results should be substantiated in further prospective and ideally multicentric studies.

\section{Disclosure Statement}

The authors declare no conflict of interest.

\section{References}

1 Koelewijn JM, Vrijkotte TG, van der Schoot CE, Bonsel GJ, de Haas M: Effect of screening for red cell antibodies, other than anti-D, to detect hemolytic disease of the fetus and newborn: a population study in the Netherlands. Transfusion 2008;48:941-952.

2 Markham KB, Rossi KQ, Nagaraja HN, O’Shaughnessy RW: Hemolytic disease of the fetus and newborn due to multiple maternal antibodies. Am J Obstet Gynecol 2015;213:68.e61-65.

3 Gottvall T, Filbey D: Alloimmunization in pregnancy during the years 1992-2005 in the central west region of Sweden. Acta Obstet Gynecol Scand 2008;87:843848.

4 Sürücü G, Mayer B, Märzacker A, Yürek S, Salama A: Harmless pregnancy-induced warm autoantibodies to red blood cells. Transfus Med Hemother 2015;42:325327

5 Heddle NM, Klama L, Frassetto R, O’Hoski P, Leaman B: A retrospective study to determine the risk of red cell alloimmunization and transfusion during pregnancy. Transfusion 1993;33:217-220.

6 Chatziantoniou V, Heeney N, Maggs T, Rozette C, Fountain C, Watts T, Harrison C, Pasupathy D, Sankaran S, Kyle P, Robinson S: A descriptive singlecentre experience of the management and outcome of maternal alloantibodies in pregnancy. Transfus Med 2017;27:275-285.

7 McBain RD, Crowther CA, Middleton P: Anti-D administration in pregnancy for preventing Rhesus allo- immunisation. Cochrane Database Syst Rev 2015; 9:CD000020

8 Moise KJ: Red blood cell alloimmunization in pregnancy. Semin Hematol 2005;42:169-178.

- Liley AW: Intrauterine transfusion of foetus in haemolytic disease. Br Med J 1963;2:1107-1109.

10 Rodeck CH, Kemp JR, Holman CA, Whitmore DN, Karnicki J, Austin MA: Direct intravascular fetal blood transfusion by fetoscopy in severe Rhesus isoimmunisation. Lancet 1981;i:625-627.

11 Bevis DC: Blood pigments in haemolytic disease of the newborn. J Obstet Gynaecol Br Emp 1956;63:68-75.

12 Liley AW: Liquor amnil analysis in the management of the pregnancy complicated by resus sensitization. Am J Obstet Gynecol 1961;82:1359-1370.

13 Stern Kurt, Goodman HS, Berger M: Experimental isoimmunization to hemoantigens in man. J Immunol 1961;87:189-198.

14 Oepkes D, Brand R, Vandenbussche FP, Meerman RH, Kanhai HH: The use of ultrasonography and Doppler in the prediction of fetal haemolytic anaemia: a multivariate analysis. Br J Obstet Gynaecol 1994;101:680-684.

15 Egbor M, Knott P, Bhide A: Red-cell and platelet alloimmunisation in pregnancy. Best Pract Res Clin Obstet Gynaecol 2012;26:119-132.

16 Mari G, Deter RL, Carpenter RL, Rahman F, Zimmer man R, Moise KJ, Dorman KF, Ludomirsky A, Gonzalez R, Gomez R, Oz U, Detti L, Copel JA, Bahado-Singh R, Berry S, Martinez-Poyer J, Blackwell SC: Noninvasive diagnosis by Doppler ultrasonography of fetal anemia due to maternal red-cell alloimmunization. Collaborative Group for Doppler Assessment of the Blood Velocity in Anemic Fetuses. N Engl J Med 2000;342:9-14.

17 Lindenburg IT, van Kamp IL, Oepkes D: Intrauterine blood transfusion: current indications and associated risks. Fetal Diagn Ther 2014;36:263-271.

18 Papantoniou N, Sifakis S, Antsaklis A: Therapeutic management of fetal anemia: review of standard practice and alternative treatment options. J Perinat Med 2013;41:71-82.

19 de Haas M, Thurik FF, Koelewijn JM, van der Schoot CE: Haemolytic disease of the fetus and newborn. Vox Sang 2015;109:99-113.

20 Zwiers C, Lindenburg IT, Klumper FJ, de Haas M, Oepkes D, van Kamp IL: Complications of intrauterine intravascular blood transfusions: lessons learned after 1678 procedures. Ultrasound Obstet Gynecol 2017;50: 180-186.

21 Zwiers C, van Kamp I, Oepkes D, Lopriore E: Intrauterine transfusion and non-invasive treatment options for hemolytic disease of the fetus and newborn - review on current management and outcome. Expert Rev Hematol 2017;10:337-344.

22 Deka D, Dadhwal V, Sharma AK, Shende U, Agarwal S, Agarwal R, Vanamail P: Perinatal survival and procedure-related complications after intrauterine transfusion for red cell alloimmunization. Arch Gynecol Obstet 2016;293:967-973. 
23 Canlorbe G, Macé G, Cortey A, Cynober E, Castaigne V, Larsen M, Mailloux A, Carbonne B: Management of very early fetal anemia resulting from red-cell alloimmunization before 20 weeks of gestation. Obstet Gynecol 2011;118:1323-1329.

24 Yinon Y, Visser J, Kelly EN, Windrim R, Amsalem H, Seaward PG, Ryan G: Early intrauterine transfusion in severe red blood cell alloimmunization. Ultrasound Obstet Gynecol 2010;36:601-606.

25 Poissonnier MH, Picone O, Brossard Y, Lepercq J: Intravenous fetal exchange transfusion before 22 weeks of gestation in early and severe red-cell fetomaternal alloimmunization. Fetal Diagn Ther 2003;18:467-471.

26 Liao C, Wei J, Li Q, Li L, Li J, Li D: Efficacy and safety of cordocentesis for prenatal diagnosis. Int J Gynaecol Obstet 2006;93:13-17.

-27 Tiblad E, Kublickas M, Ajne G, Bui TH, Ek S, Karlsson A, Wikman A, Westgren M: Procedure-related complications and perinatal outcome after intrauterine transfusions in red cell alloimmunization in Stockholm. Fetal Diagn Ther 2011;30:266-273.

28 Sainio S, Nupponen I, Kuosmanen M, Aitokallio-Tallberg A, Ekholm E, Halmesmäki E, Orden MR, Palo P, Raudaskoski T, Tekay A, Tuimala J, Uotila J, Stefanovic V: Diagnosis and treatment of severe hemolytic disease of the fetus and newborn: a 10-year nationwide retrospective study. Acta Obstet Gynecol Scand 2015;94:383-390.

29 Van Kamp IL, Klumper FJ, Oepkes D, Meerman RH, Scherjon SA, Vandenbussche FP, Kanhai HH: Complications of intrauterine intravascular transfusion for fetal anemia due to maternal red-cell alloimmunization. Am J Obstet Gynecol 2005;192:171-177.

30 Rewald E, Suringar F: Substitutive-inhibitory gamma globulin therapy as prevention of stillbirth in Rh-incompatibility. Acta Haematol 1965;34:209-214.

-31 Wagner T, Bernaschek G, Geissler K: Inhibition of megakaryopoiesis by Kell-related antibodies. N Engl J Med 2000;343:72.

32 Moise KJ, Argoti PS: Management and prevention of red cell alloimmunization in pregnancy: a systematic review. Obstet Gynecol 2012;120:1132-1139.

33 Vaughan JI, Manning M, Warwick RM, Letsky EA, Murray NA, Roberts IA: Inhibition of erythroid progenitor cells by anti-Kell antibodies in fetal alloimmune anemia. N Engl J Med 1998;338:798-803.

34 Toivanen P, Hirvonen T: Antigens Duffy, Kell, Kidd, Lutheran and Xg a on fetal red cells. Vox Sang 1973;24: 372-376.

35 Grant SR, Kilby MD, Meer L, Weaver JB, Gabra GS, Whittle MJ: The outcome of pregnancy in Kell alloimmunisation. BJOG 2000; 107:481-485.

36 Wong KS, Connan K, Rowlands S, Kornman LH, Savoia HF: Antenatal immunoglobulin for fetal red blood cell alloimmunization. Cochrane Database Syst Rev 2013;5:CD008267.

- 37 de la Cámara C, Arrieta R, González A, Iglesias E, Omeñaca F: High-dose intravenous immunoglobulin as the sole prenatal treatment for severe $\mathrm{Rh}$ immunization. N Engl J Med 1988;318:519-520.

- 38 Scott JR, Branch DW, Kochenour NK, Ward K: Intravenous immunoglobulin treatment of pregnant patients with recurrent pregnancy loss caused by antiphospholipid antibodies and Rh immunization. Am J Obstet Gynecol 1988;159:1055-1056.

39 Berlin G, Selbing A, Ryden G: Rhesus haemolytic disease treated with high-dose intravenous immunoglobulin. Lancet 1985;i:1153.

40 Berlin G, Selbing A, Gottvall T: Plasma exchange and high-dose i.v. immunoglobulin in the treatment of severe rhesus hemolytic disease. Prog Clin Biol Res 1990; 337:337-340.
41 Margulies M, Voto LS, Mathet E: High-dose intravenous IgG for the treatment of severe rhesus alloim munization. Vox Sang 1991;61:181-189.

42 Gottvall T, Selbing A: Alloimmunization during pregnancy treated with high dose intravenous immunoglobulin. Effects on fetal hemoglobin concentration and anti-D concentrations in the mother and fetus. Acta Obstet Gynecol Scand 1995;74:777-783.

43 Deka D, Buckshee K, Kinra G: Intravenous immunoglobulin as primary therapy or adjuvant therapy to intrauterine fetal blood transfusion: a new approach in the management of severe $\mathrm{Rh}$-immunization. J Obstet Gynaecol Res 1996;22:561-567.

44 Voto LS, Mathet ER, Zapaterio JL, Orti J, Lede RL, Margulies M: High-dose gammaglobulin (IVIG) followed by intrauterine transfusions (IUTs): a new alternative for the treatment of severe fetal hemolytic disease. J Perinat Med 1997;25:85-88

45 Porter TF, Silver RM, Jackson GM, Branch DW, Scott JR: Intravenous immune globulin in the management of severe Rh D hemolytic disease. Obstet Gynecol Surv 1997;52:193-197.

46 Fernández-Jiménez MC, Jiménez-Marco MT, Hernández D, González A, Omeñaca F, de la Cámara C: Treatment with plasmapheresis and intravenous immunoglobulin in pregnancies complicated with anti-PP1Pk or anti-K immunization: a report of two patients. Vox Sang 2001;80:117-120.

47 Palfi M, Hildén JO, Matthiesen L, Selbing A, Berlin G: A case of severe $\mathrm{Rh}$ (D) alloimmunization treated by intensive plasma exchange and high-dose intravenous immunoglobulin. Transfus Apher Sci 2006;35:131136.

48 Ruma MS, Moise KJ, Kim E, Murtha AP, Prutsman WJ, Hassan SS, Lubarsky SL: Combined plasmapheresis and intravenous immune globulin for the treatment of severe maternal red cell alloimmunization. Am J Obstet Gynecol 2007;196:138.e131-136.

49 Novak DJ, Tyler LN, Reddy RL, Barsoom MJ: Plasma pheresis and intravenous immune globulin for th treatment of $\mathrm{D}$ alloimmunization in pregnancy. J Clin Apher 2008;23:183-185.

50 Fox C, Martin W, Somerset DA, Thompson PJ, Kilby MD: Early intraperitoneal transfusion and adjuvant maternal immunoglobulin therapy in the treatment of severe red cell alloimmunization prior to fetal intravascular transfusion. Fetal Diagn Ther 2008;23:159-163.

51 Connan K, Kornman L, Savoia H, Palma-Dias R, Rowlands S: IVIG - is it the answer? Maternal administration of immunoglobulin for severe fetal red blood cell alloimmunisation during pregnancy: a case series. Aust N Z J Obstet Gynaecol 2009;49:612-618.

52 Isojima S, Hisano M, Suzuki T, Sago H, Murashima A, Yamaguchi K: Early plasmapheresis followed by high dose $\gamma$-globulin treatment saved a severely Rho-incompatible pregnancy. J Clin Apher 2011;26:216-218.

53 Fernández Alba JJ, León R, González-Macías C, Paz A, Prado F, Moreno LJ, Torrejón R: Treatment of D alloimmunization in pregnancy with plasmapheresis and intravenous immune globulin: case report. Transfus Apher Sci 2014;51:70-72

54 Bellone M, Boctor FN: Therapeutic plasma exchange and intravenous immunoglobulin as primary therapy for $\mathrm{D}$ alloimmunization in pregnancy precludes the need for intrauterine transfusion. Transfusion 2014;54: 2118-2121.

55 Houston BL, Govia R, Abou-Setta AM, Reid GJ, Hadfield M, Menard C, Noyd J, Main S, Zarychanski R: Severe Rh alloimmunization and hemolytic disease of the fetus managed with plasmapheresis, intravenous immunoglobulin and intrauterine transfusion: a case report. Transfus Apher Sci 2015;53:399-402.
56 Colpo A, Tison T, Gervasi MT, Vio C, Vicarioto M, De Silvestro G, Marson P: Personalized treatment with immunoadsorption and intravenous immunoglobulin in a case of severe $\mathrm{Rh}$ alloimmunization during pregnancy unresponsive to plasma - exchange. Transfus Apher Sci 2017;56:480-483.

57 Nwogu LC, Moise KJ, Klein KL, Tint H, Castillo B, Bai Y: Successful management of severe red blood cell alloimmunization in pregnancy with a combination of therapeutic plasma exchange, intravenous immune globulin, and intrauterine transfusion. Transfusion 2018;58:677-684.

58 Chitkara U, Bussel J, Alvarez M, Lynch L, Meisel RL, Berkowitz RL: High-dose intravenous gamma globulin: does it have a role in the treatment of severe erythroblastosis fetalis? Obstet Gynecol 1990;76:703-708.

59 Palmeira P, Quinello C, Silveira-Lessa AL, Zago CA, Carneiro-Sampaio M: IgG placental transfer in healthy and pathological pregnancies. Clin Dev Immunol 2012;2012:985646.

60 Anderson D, Ali K, Blanchette V, Brouwers M, Couban S, Radmoor P, Huebsch L, Hume H, McLeod A, Meyer R, Moltzan C, Nahirniak S, Nantel S, Pineo G, Rock G: Guidelines on the use of intravenous immune globulin for hematologic conditions. Transfus Med Rev 2007;21(2 suppl 1):S9-56.

61 Moise KJ: Non-anti-D antibodies in red-cell alloimmunization. Eur J Obstet Gynecol Reprod Biol 2000; 92:75-81.

62 Ballow M: Mechanisms of action of intravenous immunoglobulin therapy and potential use in autoimmune connective tissue diseases. Cancer 1991;68: $1430-1436$.

63 Janssens HM, de Haan MJ, van Kamp IL, Brand R, Kanhai HH, Veen S: Outcome for children treated with fetal intravascular transfusions because of severe blood group antagonism. J Pediatr 1997;131:373-380.

64 Mollison PL: Blood Transfusion in Clinical Medicine, 5th ed. Oxford, Blackwell Scientific Publications, 1972.

65 Schwab I, Nimmerjahn F: Intravenous immunoglobulin therapy: how does IgG modulate the immune system? Nat Rev Immunol 2013;13:176-189.

66 Yu Z, Lennon VA: Mechanism of intravenous immune globulin therapy in antibody-mediated autoimmune diseases. N Engl J Med 1999;340:227-228.

67 Dooren MC, van Kamp IL, Scherpenisse JW, Brand R, Ouwehand WH, Kanhai HH, Engelfriet CP, Gravenhorst JB: No beneficial effect of low-dose fetal intravenous gammaglobulin administration in combination with intravascular transfusions in severe Rh D haemolytic disease. Vox Sang 1994;66:253-257.

68 Kriplani A, Malhotra Singh B, Mandal K: Fetal intravenous immunoglobulin therapy in rhesus hemolytic disease. Gynecol Obstet Invest 2007;63:176-180.

69 Ulm B, Kirchner L, Svolba G, Jilma B, Deutinger J, Bernaschek G, Panzer S: Immunoglobulin administration to fetuses with anemia due to alloimmunization to D. Transfusion 1999;39:1235-1238.

70 Smits-Wintjens VE, Walther FJ, Rath ME, Lindenburg IT, te Pas AB, Kramer CM, Oepkes D, Brand A, Lopriore $\mathrm{E}$ : Intravenous immunoglobulin in neonates with rhesus hemolytic disease: a randomized controlled trial. Pediatrics 2011;127:680-686.

71 Voto LS, Sexer H, Ferreiro G, Tavosnanska J, Orti J, Mathet ER, Margulies M: Neonatal administration of high-dose intravenous immunoglobulin in rhesus hemolytic disease. J Perinat Med 1995;23:443-451.

72 Corvaglia L, Legnani E, Galletti S, Arcuri S, Aceti A, Faldella G: Intravenous immunoglobulin to treat neonatal alloimmune haemolytic disease. J Matern Fetal Neonatal Med 2012;25:2782-2785. 